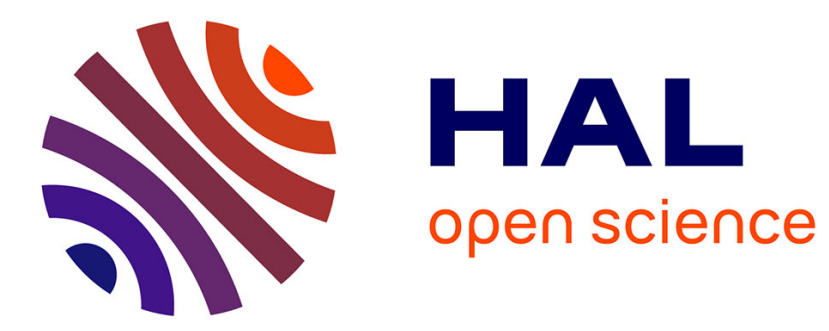

\title{
A Premartensitic Anomaly in Ni2MnGa Alloys Studied by Dynamic Mechanical Analysis
}

C. Segui, E. Cesari, J. Pons, V. Chernenko, V. Kokorin

\section{To cite this version:}

C. Segui, E. Cesari, J. Pons, V. Chernenko, V. Kokorin. A Premartensitic Anomaly in Ni2MnGa Alloys Studied by Dynamic Mechanical Analysis. Journal de Physique IV Proceedings, 1996, 06 (C8), pp.C8-381-C8-384. 10.1051/jp4:1996881 . jpa-00254689

\section{HAL Id: jpa-00254689 https://hal.science/jpa-00254689}

Submitted on 1 Jan 1996

HAL is a multi-disciplinary open access archive for the deposit and dissemination of scientific research documents, whether they are published or not. The documents may come from teaching and research institutions in France or abroad, or from public or private research centers.
L'archive ouverte pluridisciplinaire HAL, est destinée au dépôt et à la diffusion de documents scientifiques de niveau recherche, publiés ou non, émanant des établissements d'enseignement et de recherche français ou étrangers, des laboratoires publics ou privés. 


\title{
A Premartensitic Anomaly in $\mathbf{N i}_{2} \mathbf{M n G a}$ Alloys Studied by Dynamic Mechanical Analysis
}

\author{
C. Segui, E. Cesari, J. Pons, V.A. Chernenko* and V.V. Kokorin* \\ Departament de Fisica, Univ. de les Illes Balears, 07071 Palma de Mallorca, Spain \\ * Institute of Magnetism, Vernadsky str. 36 B, Kiev 252680, Ukraine
}

\begin{abstract}
Two successive anomalies in the temperature dependence of internal friction (IF) and elastic modulus have been detected for certain off-stoichiometric $\mathrm{Ni}_{2} \mathrm{MnGa}$ shape memory alloys both on cooling and heating between the parent and martensite phases. According to the transmission electron microscopy (TEM) observations these anomalies are related to two structural transformations, namely $P \rightarrow I$ and $I \rightarrow M$, where $I$ is an intermediate cubic phase obtained by $<1 / 3 \quad 1 / 3 \quad 0>$ transverse displacement modulations of the parent $P$ phase. As for the $\mathbb{I F}$ results, the $I$ to $M$ transformation behaves as a first order phase transition, whereas the $P \rightarrow I$ transition shows some distinctive features such as no temperature-rate dependence of the IF peak.
\end{abstract}

\section{INTRODUCTION}

The ferromagnetic Heusler alloy $\mathrm{Ni}_{2} \mathrm{MnGa}$ undergoes a thermoelastic martensitic transformation (MT) and associated shape memory effect. The transformation temperatures and characteristics shown by the offstoichiometric $\mathrm{Ni}_{2} \mathrm{MnGa}$ alloys can be varied by means of small composition changes [1], allowing for classification of the alloys into groups depending on transformation temperatures. The Ni-Mn-Ga alloys belonging to the different groups also show different mechanical behaviour both in the martensitic phase and in the transformation region. Particularly, the alloys with the lowest transformation temperatures (about $200 \mathrm{~K}$ ) show two consecutive internal friction (IF) maxima and corresponding Young modulus minima, which occur at different temperature ranges both on cooling and heating the samples. Precursor phenomena and soft mode behaviour in the premartensitic region of these alloys have been already studied and attributed to the existence of an intermediate phase between the parent and the martensite [2-4], but experimental evidence for mechanical properties change related to a phase transition other than the martensitic one have not been reported until now.

In this paper the IF and modulus results concerning both the premartensitic and martensitic transformations will be shown and analyzed with the help of TEM observations, and their characteristics and nature will be discussed.

\section{EXPERIMENTAL PROCEDURE}

Several off-stoichiometric $\mathrm{Ni}_{2} \mathrm{MnGa}$ alloys with $\mathrm{M}_{\mathrm{s}}$ about $200 \mathrm{~K}$ and Curie temperature about $380 \mathrm{~K}$ were studied, but since it was found that all of them show similar IF behaviour near the MT irrespectively to their single or polycrystalline state, the results presented below correspond mainly to one of the alloys, a single crystal with nominal composition $\mathrm{Ni}-24.3 \mathrm{Mn}-26.0 \mathrm{Ga}$ at.\%. The martensitic transformation temperatures as measured by low field magnetic susceptibility technique resulted to be $M_{S}=175 \mathrm{~K}$ and 
$A_{S}=190 \mathrm{~K}, M_{S}$ and $A_{S}$ being the start temperatures of the forward and reverse martensitic transformations respectively.

The dynamic mechanical properties of the alloys were studied in three-point bending configuration using a Perkin-Elmer Dynamic Mechanical Analyzer, DMA-7. Plate-like specimens of average dimensions $10 \mathrm{x}$ $1.5 \times 0.5 \mathrm{~mm}^{3}$ were sparkcut, mechanically polished by grinding and electropolished as a final stage of the preparation. The phase difference $(\tan \delta)$ between the sinusoidal applied stress and the resulting strain gives the IF, and the elastic or storage modulus (E) is obtained as the real part of the complex modulus. The temperature dependence of IF and modulus at constant stress amplitude $\sigma$ and the stress amplitude dependence of IF at different constant temperatures were studied.

The structural identification of the different phases was performed using Transmission Electron Microscopy (Hitachi H600, 100kV) equipped with single-tilt heating and cooling stages. The thin foils were prepared by double-jet electropolishing in a $50 \%$ nitric acid in methanol at $8 \mathrm{~V}$ and $240 \mathrm{~K}$.

\section{RESULTS AND DISCUSSION}

The temperature spectrum of internal friction and storage modulus of the studied alloy during cooling is presented in Fig.1. The IF spectrum is fairly reproducible during consecutive temperature cycling. In the low temperature region the curves show the typical internal friction and modulus behaviour during MT, with a higher IF level in the martensitic phase (M) than in the high temperature phase, and an IF-peak concurrently with a modulus minimum at the transformation temperature range [5]. The same is true for the reverse MT, which proceeds with a hysteresis about $10 \mathrm{~K}$. The most outstanding feature shown in Fig. 1 is the presence of an additional IF-peak and corresponding modulus minimum at temperatures well above the MT, which are also observed during the heating runs.

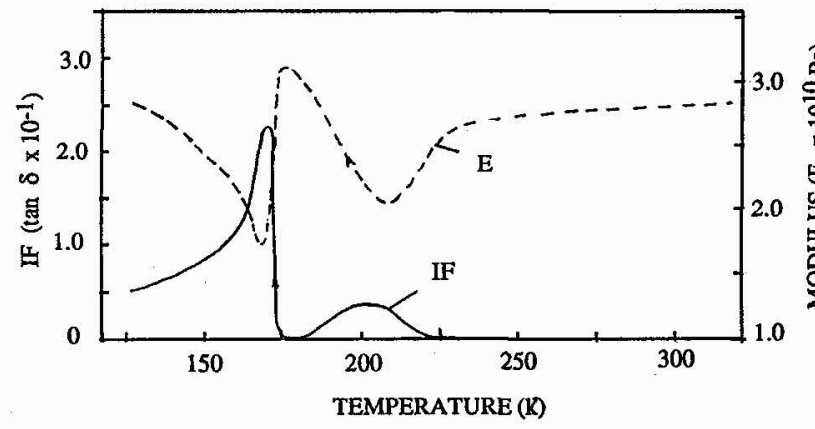

Figure 1. Evolution of the internal friction (IF) and modulus (E) during cooling for the studied Ni-Mn-Ga alloy $\left(\mathrm{T}=5 \mathrm{~K} / \mathrm{min}, \nu=2 \mathrm{~Hz}, \sigma_{o}=\right.$ $2 \mathrm{MPa})$.

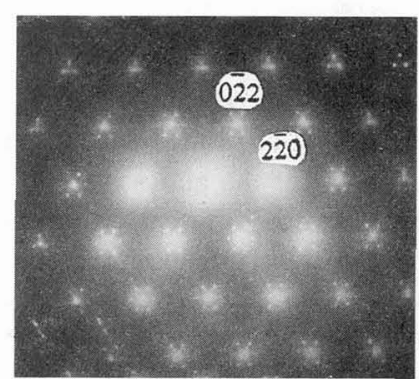

Figure 2. Selected area electron diffraction pattern obtained at $T=183 \mathrm{~K}, 1$ phase, zone axis $[111]_{p}$ indexed according to the $L 21$ structure.

The two stages in IF and E modules spectra can be attributed to two separated structural transformations, as indicated by TEM observations performed at different temperatures. Around and above $200 \mathrm{~K}$ (parent phase, P), the selected area electron diffraction patterns (SAEDP) correspond to a $L 21$ ordered cubic structure with diffuse streaking along $<110>$ directions, and a corresponding "tweed" contrast is observed in the bright field images. On cooling down, the streakings are observed to be replaced by extra sharp reflections (satellites) which divide the reciprocal lattice spacings in all $<110>$ directions in 6 equal parts, as seen in Fig. 2. The changes in SAEDP indicate the existence of a new phase (intermediate phase, I) different from the parent phase, as it was assumed in [2,3]. Recently, a further confirmation of the occurrence of I phase was found by inelastic neutron scattering measurements [4]. According to the present data, the structure of the 1 phase can be regarded as a modulated structure derived from the $P$ 
phase, with $<1 / 3 \quad 1 / 3 \quad 0>$ transverse displacement modulations (wavelength of $6\{110\}$ atomic planes). The HREM images reported in [4] show an inhomogeneous assembly of contiguous distorted regions of roughly 4-6 $\mathrm{nm}$ in size. On further in-situ cooling, the transformation to martensite phase $(M)$ is observed, with the development of a plate microstructure. The SAEDP reveal a tetragonal lattice with long period modulations along $\langle 001\rangle_{\text {tetr, }}$, which needs a further detailed investigation to clarify its stacking order structure, although it is clear that the modulation is different from the one observed in the I phase. The whole P-I-M transformation path is reversible on in-situ heating.

Thus, it is shown in the present work that forward and reverse phase transformations between $\mathbf{P}$ and $\mathbf{I}$, characterized by changes of the physical properties such as the IF and modulus, occur at temperatures above the martensitic transformation. It is worth noting that the $P \leftrightarrow I$ transformation takes place independently on the MT, as stated from DMA and in-situ TEM experiments in which cooling was stopped between the two IF peaks and the specimen was heated back to the parent phase. The hysteresis of this transformation as measured from IF peaks resulted to be about $3 \mathrm{~K}$. However, in DSC experiments only the MT was detected, traces of the $\mathrm{P} \leftrightarrow \mathrm{I}$ transformation being completely absent regardless of the temperature rate.

Additional experiments were undertaken to get some information about the IF behaviour as a function of external parameters in martensite, I-phase and transformation regions. The results can be summarized as follows:

(1) The IF peak height relative to the IF level in martensite decreases with increasing stress amplitude for the MT, while in the case of the $P \rightarrow I$ transition the IF maximum with respect to the I-phase level is nearly stress amplitude independent, as seen in Fig. 3.

(2) The $I \rightarrow M$ transformation can be stress induced at constant temperature, as pointed out from the experiments of stress amplitude dependence of $\tan \delta$ and strain at constant temperature in the I phase (Fig. 4); the values of the stress amplitude corresponding to the maxima are linearly dependent on temperature.

(3) The IF values drop about $10 \%$ when cooling is arrested during the MT and the temperature is maintained constant, as it can be seen in Fig. 5.a. From this it can be concluded that a small but non-zero temperature rate contribution to the IF exists during the MT. On the contrary, almost no changes in IF are observed in similar experiments performed during the $\mathrm{P} \rightarrow \mathrm{I}$ transition, as seen in Fig. 5,b, and therefore the IF is temperature rate independent in this case. The same results arise from systematic measurement of IF vs temperature at different temperature rates between 1 and $10 \mathrm{~K} / \mathrm{min}$.

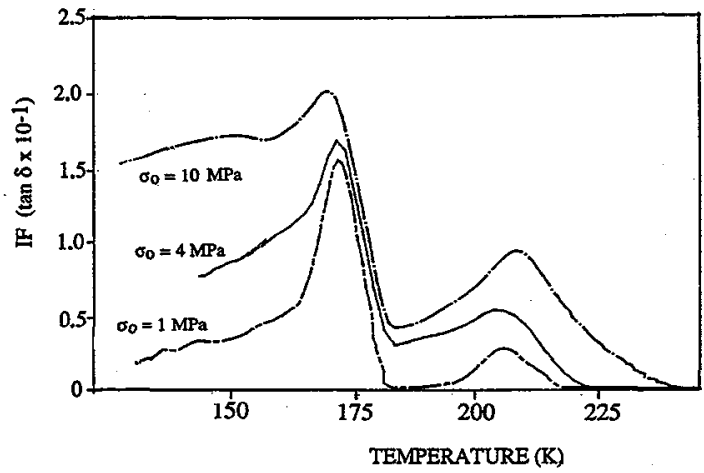

Figure 3. Temperature evolution on cooling of the IF under different stress amplitudes $(v=1 \mathrm{~Hz}, \dot{\mathrm{T}}=5 \mathrm{~K} / \mathrm{min})$

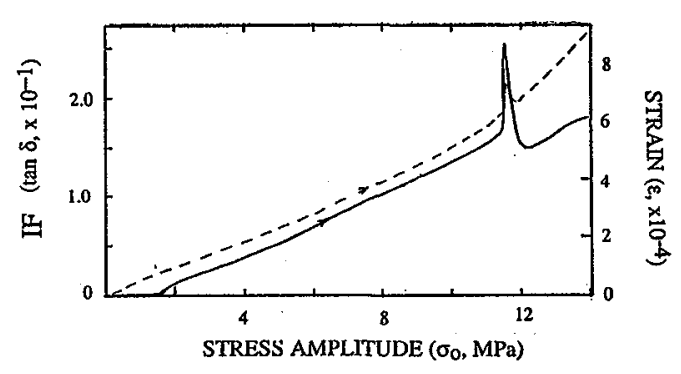

Figure 4. Stress amplitude dependence of the IF (continuous lines) and strain (discontinuous lines) at constant temperature in 1 phase $\left(l^{\prime}=190 \mathrm{~K} .(v=1 \mathrm{~Hz}\right.$, force rate $50 \mathrm{mN} / \mathrm{min}$ ). 
The IF peak associated with a first order transformation (and among them the MT) has been extensively studied [5-8], a transient contribution $\left(\mathrm{IF}_{\mathrm{tr}}\right)$ being recognized as imperative. This contribution exists only during cooling or heating and is proportional to the volume fraction transformed per unit time, depending on external parameters like temperature rate, frequency and stress amplitude. According to the above results the $\mathrm{I} \rightarrow \mathrm{M}$ transition agrees with the general scheme of a first order transformation, even though the temperature rate contribution to the IF peak is much smaller than obtained for other alloys undergoing a MT. The existence of a definite microstructural change and detectable latent heat also confirm the first order behaviour. On the contrary, for the $\mathrm{P} \rightarrow \mathrm{I}$ transformation features like $i$ ) absence of temperature rate dependence of IF (null IF $_{\mathrm{tr}}$ contribution); ii) absence of a discontinuous microstructural change accompanying the transformation and iii) absence of detectable latent heat, depart from the characteristics of a first order transition, although the existence of a corresponding IF peak and modulus minimum points, in principle, to a first order transition.
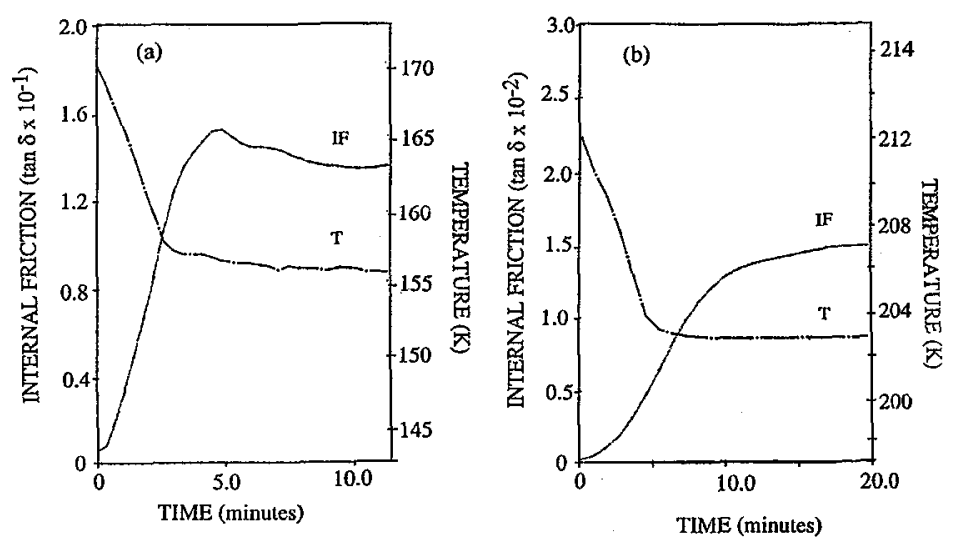

Figure 5. Effect of the temperature rate on the IF; the time evolution of $\tan \delta$ as cooling is arrested and the temperature is maintained constant during the MT transformation (a) and the $P \rightarrow I$ transformation (b) is studied.

\section{Acknowledgments.}

V.A. Chernenko is grateful to the UIB for financing his stay at the Departament de Física. Partial financial support from the Spanish CICYT (research project MAT93-0188) and DGICYT (PB94-1173) is acknowledged.

\section{References}

[1] V.A. Chernenko, E. Cesari, V.V. Kokorin, I.N. Vitenko, Scripta Met. et Mat. 33, 1239 (1995).

[2] V.V. Kokorin, V.V. Martynov, V.A. Chernenko, Scripta Met. et Mat.. 26, 175 (1992).

[3] G. Fritsch, V.V. Kokorin, J. Kempf, .J. Phys: Condens. Matter 6, L107 (1994).

[4] A. Zheludev, S.M. Shapiro, P. Wochner, A. Schwarz, M. Wall, L.E. Tanner, Phys Rev. B 51, 11310 (1995) and J. de Physique IV 5, C8-1139 (1995).

[5] J. Van Humbeeck, Proc. 9th Int. Conf. on Internal Friction and Ultrasonic Attemuation in Solids; Ed. by T.S. Ke, International Academic Publishers, p. 337 (1989).

[6] J.F. Delorme, P.F. Gobin, Metaux No. 573, p.185 (1973) and No. 574, p. 209 (1973).

[7] W. Dejonghe, R. De Batist, L. Delaey, Scripta Met. 10, 1125 (1976).

[8] J.E. Bidaux, R. Schaller, W. Benoit, Acta Met. 37, 803 (1989). 